\title{
The fate of eyes with wet AMD beyond four years of anti-VEGF therapy
}

\author{
Justus G. Garweg ${ }^{1,2}$ · Johanna J. Zirpel ${ }^{2} \cdot$ Christin Gerhardt $^{1,2} \cdot$ Isabel B. Pfister ${ }^{1,2}$ \\ Received: 25 October 2017 / Revised: 27 December 2017 / Accepted: 10 January 2018 / Published online: 3 February 2018 \\ (C) Springer-Verlag GmbH Germany, part of Springer Nature 2018
}

\begin{abstract}
Purpose Real-life studies on long-term functional outcome of anti-VEGF treatment for wet age-related macular degeneration (wAMD) are limited. We therefore assessed the 10-year outcomes in our patients.

Methods In this retrospective study, all patients with newly diagnosed wAMD that had received minimally three intravitreal injections between 2007 and 2012 and a follow-up of $\geq 48$ months were included. Primary outcome measure was the evolution of best-corrected visual acuity (BCVA) over time. For qualitative, quantitative and longitudinal data, Pearson's chi ${ }^{2}$ test, the MannWhitney U-test and Wilcoxon's signed-rank test were applied at a significance level of $p<0.05$.

Results Of 267 eyes (219 patients) with newly diagnosed wAMD treated during this period, 104 eyes (104 patients) had been followed for at least 48 months and were included. Fifty-nine eyes (57.8\%) after 7 years were still under active treatment, 29 eyes (25.0\%) had interrupted treatment [mean follow-up 7.5 years (4.0-10.1; SD 1.6)], whereas 16 patients had died. BCVA stabilized at -7.3 to -11.9 letters after $3-10$ years of follow-up with a mean of 2.8 injections (median; 3.0, SD 1.0;1-5) and 5.1 visits per year. In two thirds of eyes, treatment was switched to aflibercept or corticosteroid combinations without bearing on functional outcomes. Thirty-seven percent (37\%) of eyes maintained driving vision for up to 10 years.

Conclusions Beyond 3 years of treatment, functional stability was maintained for up to 10 years. Further improvement of longterm outcomes might have required a more intensive treatment in the early phase.
\end{abstract}

Keywords Aflibercept · Intravitreal injections - Long-term treatment · Ranibizumab - Wet age-related macular degeneration · WAMD

\section{Introduction}

If left untreated, wet age-related macular degeneration (wAMD) leads to a severe loss of visual acuity [1]. If suitably treated, the functional status is stabilized and correlates closely with a sufficient and permanent suppression of choroidal neovascularization $(\mathrm{CNV})$ and growth $[2,3]$. Notwithstanding these encouraging results, atrophy of the macula occurs in virtually $100 \%$ of VEGF-treated eyes, irrespective of the choice of therapeutic regime, with the consequence that visual acuity deteriorates significantly after an initial improvement [4-7]. With a view to improving the long-term functional

Justus G. Garweg

Justus.garweg@augenklinik-bern.ch

1 Swiss Eye Institute, Rotkreuz, and Berner Augenklinik am Lindenhofspital, Bremgartenstrasse 119, CH-3012 Bern, Switzerland

2 University of Bern, Bern, Switzerland outcome of treatment with anti-VEGF agents, an assessment of the factors that impact the results of their chronic therapeutic use is thus justified.

Since the first reports on the systemic [8] and the local [9] use of anti-VEGF agents for the treatment of wAMD appeared, two such drugs have been approved for this purpose: ranibizumab in 2007 [10-12] and aflibercept in 2012 [13, 14]. Not surprisingly, long-term data spanning more than 5 years are available only for the former [15]. The first reported set of long-term data is derived from the follow-up of the Anchor and Marina study population. Although the analysis was based on only $10 \%$ of the original population, the unexpected worsening of the visual outcome with the passage of time was disquieting and triggered heated discussions on the risk-tobenefit ratio and the long-term therapeutic strategy that would be best suited to stabilize the initial visual gain without leading to macular atrophy. A comparison of the study and the partner eyes in Anchor and Marina's population revealed the partner eyes, which had undergone less intensive treatment during the first 2 years, to have poorer visual outcomes and more 
pronounced atrophy than the study eyes, which had received monthly injections [16]. This finding indicates that macular atrophy is not only linked to treatment, but also a part of the natural progression of the disease, since the patients were older and presumably less healthy at the later stage than at the earlier juncture [17]. The fear that the long-term use of ranibizumab would induce side-effects led to caution and under-treatment, which may partially explain why studies reporting on real-world experience with anti-VEGF therapy are so outnumbered by controlled sponsor-initiated clinical trials appertaining thereto [5, 18-25]. Regression analyses of these data reveal that, in addition to the age of the patient and the visual acuity at the onset of treatment, compliance with the scheduled visits and the therapeutic regime are crucial outcome predictors in real life [26, 27]. The aim of the present study was to retrospectively assess the long-term outcomes of our own patients in whom intravitreal treatment with ranibizumab for wAMD had been initiated before 2013. In doing so, we are, of course, fully aware that during the intervening period, changes in treatment and patient guidance have been affected in many cases which renders a comparison of treatments meaningless.

\section{Patients and methods}

In this retrospective study, patients with wAMD who had been treated in the macula clinic of the Berner Augenklinik am Lindenhofspital were included if they fulfilled the following criteria: (i) angiographically confirmed $\mathrm{CNV}$ in the context of wAMD requiring intravitreal therapy, as indicated by the loss of visual acuity and the manifestation of intra- and subretinal fluid in OCT; (ii) treatment with minimally three intravitreal injections of ranibizumab and thereafter as needed according to SD-OCT-based anatomical findings (with the aim of stabilizing the lesion at each recurrence); and (iii) a follow-up time of minimally 48 months after the onset of therapy.

Eyes that satisfied the inclusion criteria were subdivided into three groups: those undergoing therapy with ranibizumab (group 1), those in which a switch to aflibercept had been affected after its approval for clinical use in Switzerland in December 2012 (group 2) and those which had required multiple therapies to achieve stability (absence of intraretinal fluid and absence or stability of subretinal and sub-pigment epithelial fluid), including a combination of anti-VEGF agents with intravitreally administered corticosteroids [triamcinolone 4$8 \mathrm{mg}$ per injection or Ozurdex ${ }^{\circledR}$ (Allergan), an implant bearing $0.7 \mathrm{mg}$ of dexamethasone; group 3].

The study was approved by the local regulatory authorities (Institutional Ethics Committee, University of Bern, under the reference KEK 099/15) and was conducted with the informed consent of the patients to use their coded data.

\section{Inclusion and exclusion criteria}

Patients who started treatment between January 2007 and August 2012 with a minimal follow-up period of 4 years were included in the study. Patients with underlying diseases that could interfere with the clinical outcome, namely, those with an active vascular affection (e.g., any stage of active diabetic retinopathy) or an inflammatory ocular disorder (uveitis), were excluded from the study; so, too, were those in whom the CNV was of another etiology. Individuals who had not attended the scheduled consultations were likewise excluded from the study. Patients who had not attended clinical visits for more than 6 months for any reason (futility of treatment, change in consultant, patient's decision, illness or death) were considered to be no longer undergoing active treatment. The last visit prior to the break of minimally 6 months was defined as the end of the monitoring. The data-lock for the analysis was set on January 31st, 2017. The time that elapsed between date of the diagnosis and that of the final visit was defined as the follow-up interval.

\section{Data acquisition}

Data appertaining to the patients were retrieved from their electronic records and from the OCT database entries that were linked to the corresponding visits. From these data we extracted Snellen's best-corrected visual acuities (BCVAs), which were converted to the corresponding ETDRS letter scores (with 85 letters representing a BCVA of 1.0), the intraocular pressures and the functionally relevant anatomical findings.

The measurement of central foveal thickness (CFT), as well as the investigator's classification of the macula as being either dry (absence of any fluid) or wet (any fluid in the central zone with a diameter of 1 millimeter) were based on the use of a horizontal line algorithm with a length of $6 \mathrm{~mm}$ (Spectralis $^{\mathrm{TM}}$, Heidelberg Instruments, Heidelberg, Germany). All CFT measurements were made on a micrometer scale from the inner retinal surface to Bruch's membrane, where this was visible, or where it was estimated to be if it was obscured by the hyper-reflective subretinal fibrovascular complex.

The data were collected from the time of the diagnosis until that of the final check-up before the data-lock on January 31st, 2017 (up to 11 junctures of measurement: at the time of the diagnosis and the first intravitreal injection, after 3 injections, after 12 months and thereafter annually up to 10 years). Since this study was retrospective in nature, a time window of $15 \%$ was accepted for the coincidence of the clinical visits with the study junctures. 
BCVA was presumed to have stabilized if the change in this parameter fell within a range of \pm 5 letters. A change in visual acuity was defined as slight if it spanned 6 to 14 letters. A severe deterioration in visual acuity was defined as a loss of $\geq 15$ letters, and a relevant improvement as a gain of $\geq 15$ letters, relative to the baseline values.

Missing data were supplied according to the lastobservation-carried-forward (LOCF) method, in order to assess the impact of the missing values.

\section{Statistical evaluation of the data}

Given the fact that the data were not normally distributed, a series of non-parametric tests were conducted. To compare the temporal profiles of BCVA between the groups, the Kruskal-Wallis H test was performed. Since multiple comparisons increase the risk of introducing a type-I error, the significance level was adjusted using a Bonferroni correction. To ascertain whether the visual acuity had stabilized, a Kaplan-Meier survival analysis was performed. All statistical evaluations were performed using the SPSS software package V.23 (SPSS, Inc., Chicago, IL, USA), with the level of significance being set at $p<0.05$. Unless otherwise stated, the data are represented as mean values together with the standard deviation (SD).

\section{Results}

Of the 269 eyes (219 patients) with newly diagnosed CNV that was attributable to wAMD and which underwent therapy between 2007 and 2012, 104 patients (104 eyes: 48\%) satisfied the inclusion criteria of having been first treated with ranibizumab and followed up for minimally 48 months. Sixteen of the included patients (16 eyes: $15.4 \%$ ) had died after the 4-year juncture. Of the surviving 88 patients, 59 patients (59 eyes: $56.7 \%$ ) were still undergoing active therapy at the end of the observation period and 29 patients (29 eyes: 27.9\%) were no longer under active treatment for other or unknown reasons (Fig. 1). Of the 165 eyes that had not been included, 24 were partner eyes which satisfied the inclusion criteria, but were excluded because of independence problems of these eyes, 39 had been followed for less than 48 months, 29 had not received three initial injections, and 53 eyes had returned to their local ophthalmologists for further therapy or not attended the scheduled visits. Twenty additional patients had not received ranibizumab or another pathology underlying their choroidal neovascularisation.

At diagnosis, the mean age of the patients was 77.3 years (SD 6.9; range: 53.4-93.9). The mean follow-up time was 7.5 years (SD 1.6; median 7.9; range: $3.9-10.1$ ). The initial improvement in visual acuity of 5.9 letters that was achieved after the administration of the first three injections diminished during the course of the first year, at the end of which the gain was only 2.6 letters relative to the baseline value. By the end of the following years, letters had been lost. Between years 3 and 10, the visual acuity deteriorated further, but less markedly, and the situation finally stabilized at a loss of between 7.3 and 11.9 letters (Fig. 2a). The results remained widely unchanged after applying the LOCF method (Fig. 2b). The initial visual gain decreased over time. A Kaplan-Meier survival analyses showed that $50 \%$ of the eyes had a decrease in visual function below the initial visual acuity after 3 years (Fig. $3 a)$. The portion of gainers and losers compared to baseline is depicted in Fig. 3b.

The change in central retinal thickness (CRT) was, as expected, most remarkable after the administration of the first 3 injections, with a mean decrease of $-189 \mu \mathrm{m}$ being achieved relative to the baseline value of $608 \mu \mathrm{m}$. By the end of year 1, the CRT had increased to $458 \mu \mathrm{m}$, which corresponded to a mean decrease of $-127.4 \mu \mathrm{m}$ relative to the baseline value. This reversal paralleled the decrease in ETDRS letters. Between years 2 and 10, the CRT continued to decrease. By the end of year 10, a mean value of $198 \mu \mathrm{m}$ had been achieved, which corresponded to a mean decrease of $-349 \mu \mathrm{m}$ (Fig. 4). Imputing missing data by the LOCF method did not change the outcome (data not shown).

An average of five injections (SD 2.2, range: 3-10) were administered during the course of the first year and three injections per year thereafter. This lower-thanexpected value may be partially accounted for by the circumstance during the early phase of treatment of many pseudophakic eyes (47 patients) where the administration of ranibizumab was combined with that of triamcinolone in the attempt to reduce the number of injections. The number of visits (Table 1) approached the expected values, even though many patients had their intercurrent visits in phases without treatment demand performed at their private ophthalmologists.

We also compared the temporal profiles of BCVA in patients who had been treated exclusively with ranibizumab and those who had undergone a switch in therapy, either to aflibercept or to a combination of ranibizumab and bevacizumab, triamcinolone or dexamethasone. Insignificant differences in visual acuities before treatment initiation remained during the course of treatment; the evolution of visual function over time remained similar between the groups (Fig. 5). Finally, the portion of eyes with a BCVA of 0.5 or above (driving vision) mildly regressed from 42.3 to $37.5 \%$, but remained above $30 \%$, whereas the portion of eyes with a visual acuity of 0.1 or less increased from 12.5 to $37.5 \%$ on the costs of those between 0.1 to 0.5 , which came down from 45.2 to $25.0 \%$ (Fig. 6). 
Fig. 1 Number and fate of study eyes which were followed for a minimum of 5 years, divided by group, for which data were available at each of the indicated junctures. The numbers per group represent the eyes at each time point, for which data were available

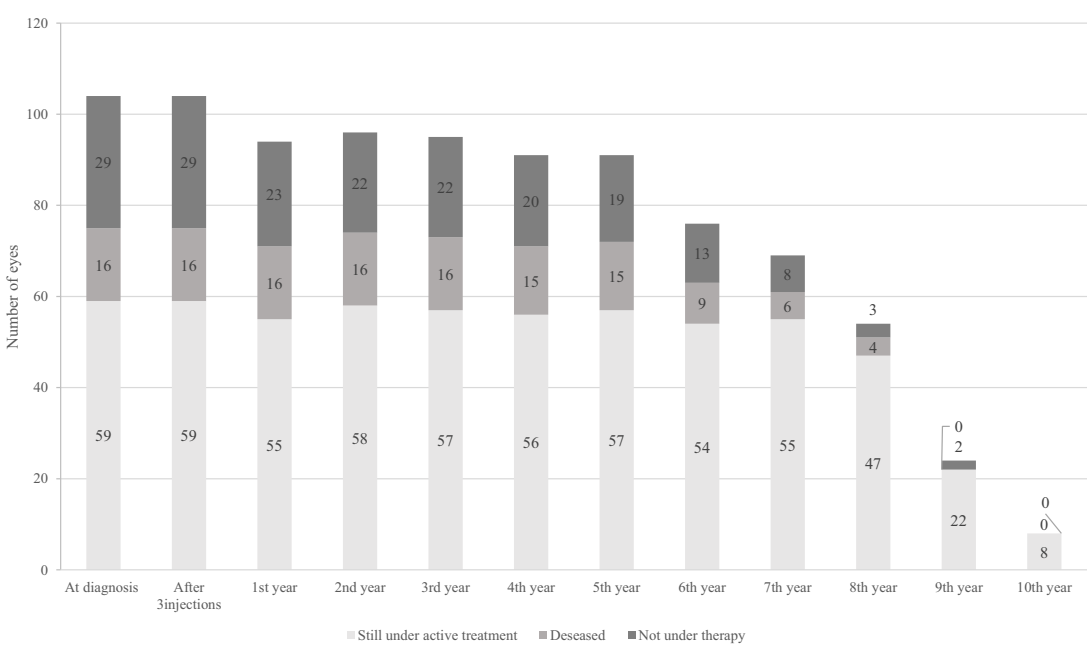

\section{Discussion}

In patients with newly diagnosed CNV attributed to wAMD, long-term treatment with ranibizumab slowed down the progression of the underlying pathology and usually permitted the maintenance of useful visual function with maintenance of driving vison $(\geq 0.5)$ in one third of eyes for up to 10 years. Though individual eye-derived factors may have played an
Fig. 2 a Temporal evolution of best-corrected visual acuity (BCVA) over time [in ETRDS letters; mean \pm standard error (SE)]. b Temporal evolution of BCVA over time (in ETRDS letters; mean \pm SE) after imputation of missing values by the last-observation-carriedforward method (LOCF; $\mathrm{n}=128$ )
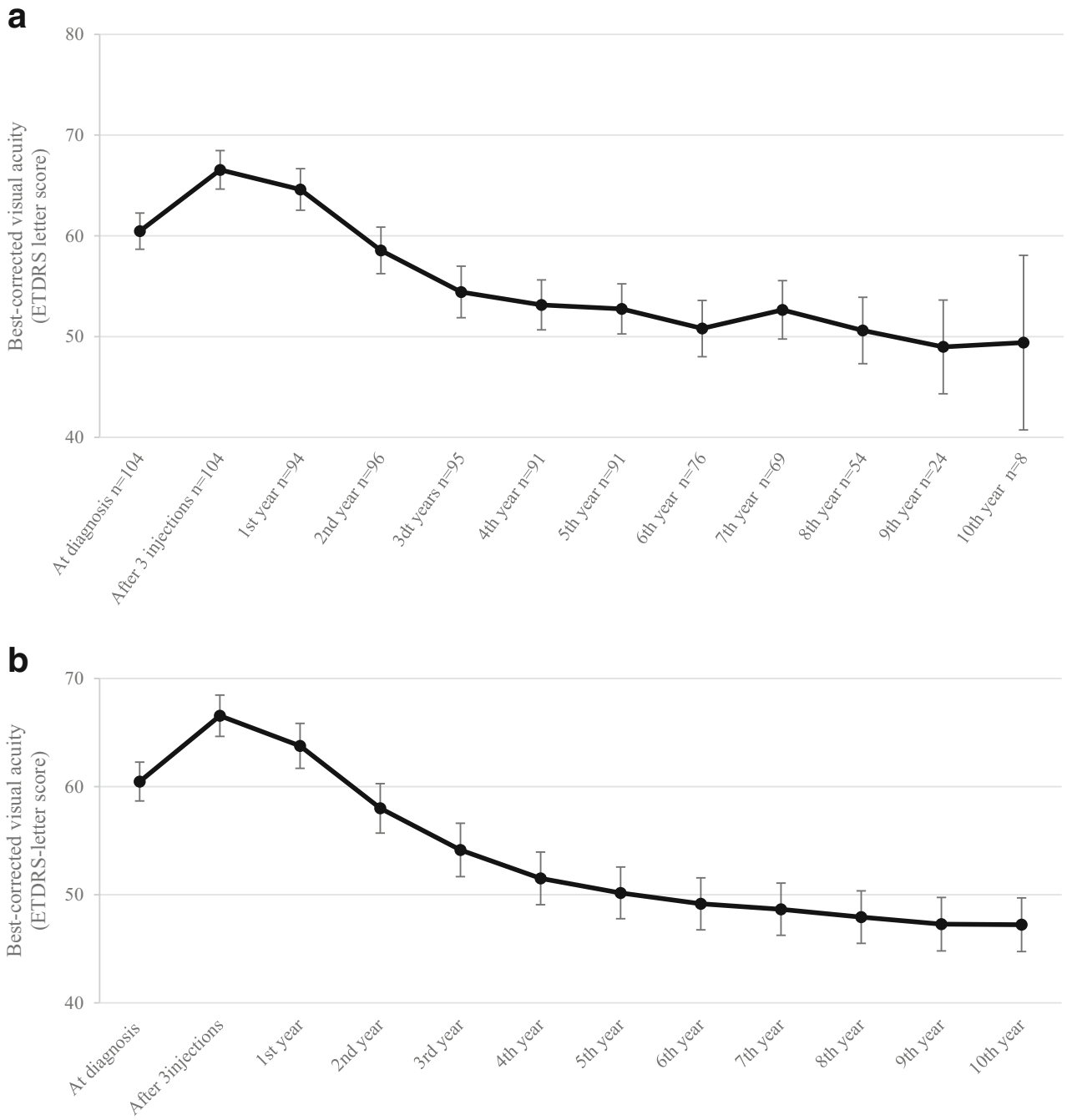
Fig. 3 a Kaplan-Meier survival plot of ETDRS letter scores.

Visual function decreased by more than 5 letters below the initial visual acuity for $50 \%$ of the eyes after 36 months. b Change in visual acuity scores over time: portion of gainers and losers
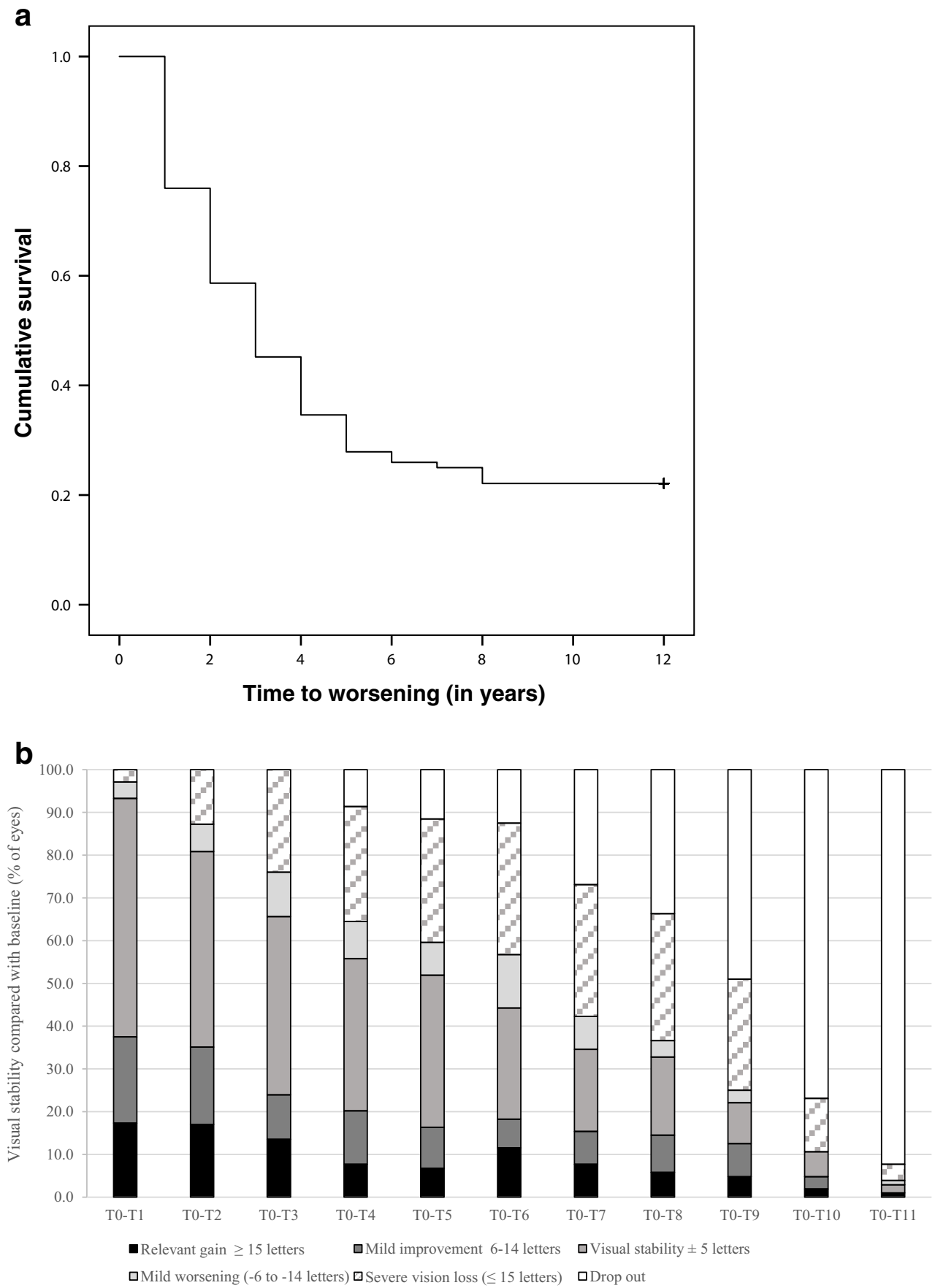

important role, our results also reflect a learning curve of how to handle patients in the real world in the absence of a real-lifesupported treatment strategy. During the first years of therapy, the number of administered injections was low, which indicates that the disease was under-treated. This circumstance accounts for the deterioration in visual acuity during the first 2 to 3 years. We were fortunate in that our patients complied closely with the scheduled visits: $87 \%$ were monitored for more than 5 years and $66 \%$ for more than 7 years (Table 1).
By the latter juncture, only $28 \%$ had been lost to follow-up, due either to non-compliance or death, whereas $7 \%$ had as yet not reached this follow-up duration. In comparison, in the Horizon study, data were available for only $10 \%$ of the primary Anchor and Marina patients at the 7-year juncture [5], which raises a doubt as to the representativity of these data. Notwithstanding this drawback, data appertaining to the functional outcomes and to the number of injections that were administered during years 3 to 7 are comparable to our own: 
Fig. 4 Temporal change in central retinal thickness

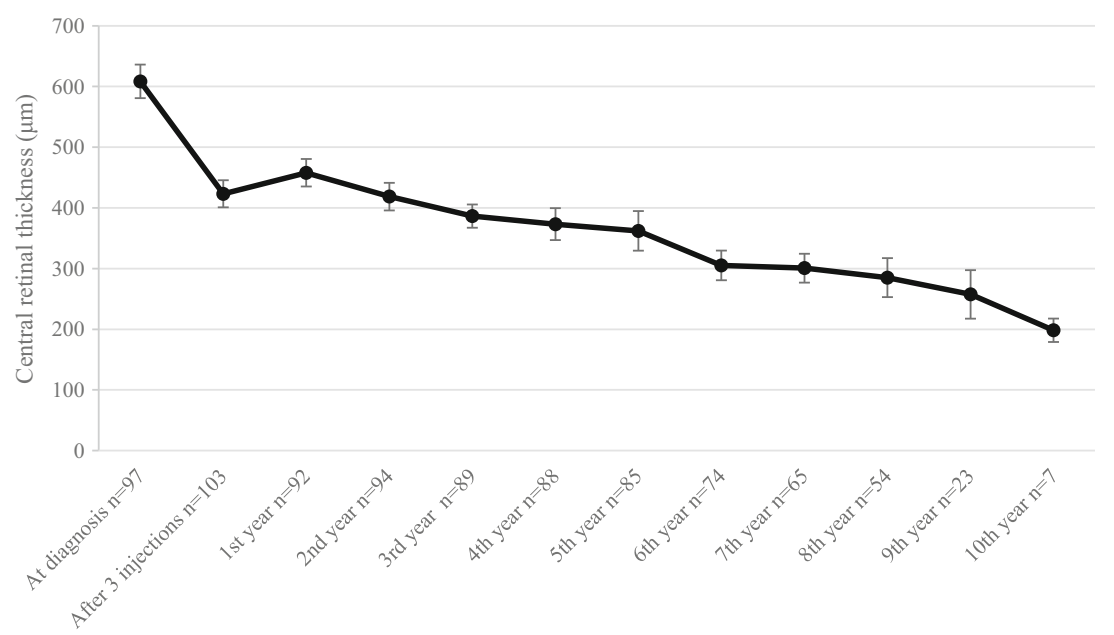

The vision loss of 8 letters compared to baseline after 7 years is similar to that seen in our patients ( -11.5 letters), but it was encountered between year 3-5 after monthly treatment for the first 2 years. In our patients, in contrast, the loss of function was encountered during the first 2-3 years and remained stable thereafter, suggesting that a more intensive early treatment would have improved our long-term outcomes as reported by several later studies [20-22]. In one of these [21], which drew on $71 \%$ of the CATT study population, a less marked loss of visual function (3 letters) was achieved in $50 \%$ of the patients during the first 2 years after the administration of monthly injections. However, in nearly $75 \%$ of the patients, a switch in therapy had been affected during the first 2 years, as an indication that the response to treatment was not entirely satisfactory. But since initial visual acuity fell within and did not surpass the expected range, an advancement of the disease or a ceiling effect due to very good initial VA may be excluded as a consequence [28]. The main differences between the findings of the Horizon and the CATT studies reflect the lessons that were learned during the intervening period not only in our patients. This may include an earliest possible treatment initiation, OCT-based retreatment decisions and a complete and continued suppression of disease activity [17, 25]. Since we managed to stabilize visual function after the initial loss for up to 10 years, the natural evolution of the disease, which was attested to by a geographic progression of the macular atrophy $[19,29,30]$, may be of less functional relevance in cases of wAMD than in those of advanced dry AMD [31].

In our patients, a mean of 7.9 clinical visits was performed within the first year, which is comparable to the number in the large retrospective Australian cohort [24]. Patients in this cohort maintained their initial visual gain over 5 years after nine visits and the administration of six intravitreal injections during the first year, and of eight visits and the administration of five intravitreal injections during each subsequent year. The consistently greater intensity of the treatment may have
Table 1 Numbers of examinations and injections per year

\begin{tabular}{|c|c|c|c|c|c|c|c|c|}
\hline \multicolumn{4}{|c|}{ Examinations per year } & \multicolumn{4}{|c|}{ Injections per year } & \multirow[t]{2}{*}{$\mathrm{N}(\%)$} \\
\hline & Mean & $\mathrm{SD}$ & Range & & Mean & SD & Range & \\
\hline 1st year & 7.9 & 2.8 & $3-15$ & 1st year & 4.9 & 2.2 & $3-10$ & $94(90.4 \%)$ \\
\hline 2nd year & 6.5 & 2.8 & $1-12$ & 2nd year & 3.2 & 2.9 & $0-11$ & $96(92.3 \%)$ \\
\hline 3rd year & 5.6 & 2.5 & $1-12$ & 3 rd year & 3.3 & 3.0 & $0-12$ & $95(91.3 \%)$ \\
\hline 4th year & 5.6 & 2.8 & $1-17$ & 4th year & 3.0 & 3.0 & $0-13$ & $91(87.5 \%)$ \\
\hline 5 th year & 4.8 & 2.6 & $1-11$ & 5 th year & 2.8 & 2.8 & $0-9$ & $91(87.5 \%)$ \\
\hline 6 th year & 4.3 & 2.3 & $1-11$ & 6 th year & 2.9 & 2.9 & $0-10$ & $76(73.1 \%)$ \\
\hline 7 th year & 4.0 & 2.4 & $1-11$ & 7th year & 2.8 & 2.8 & $0-10$ & $69(66.3 \%)$ \\
\hline 8 th year & 4.3 & 2.2 & $1-10$ & 8th year & 2.3 & 2.8 & $0-10$ & $54(51.9 \%)$ \\
\hline 9th year & 3.8 & 2.5 & $1-10$ & 9th year & 1.8 & 2.3 & $0-7$ & $24(23.1 \%)$ \\
\hline 10th year & 4.9 & 2.5 & $1-8$ & 10th year & 1.2 & 1.6 & $0-4$ & $8(7.7 \%)$ \\
\hline
\end{tabular}


Fig. 5 Temporal profiles of bestcorrected visual acuity that were recorded for the different treatment algorithms. Legend: The $*$ denotes those at which the visual acuity in the

"ranibizumab" group differed from that in either the "switch to aflibercept" or the "switch to combination therapy" group. The significance level was adjusted to $p=0.0014$ using Bonferroni's correction. In response to the small sub-group size, we had to apply the statistical option of last observation carried forward (LOCF)

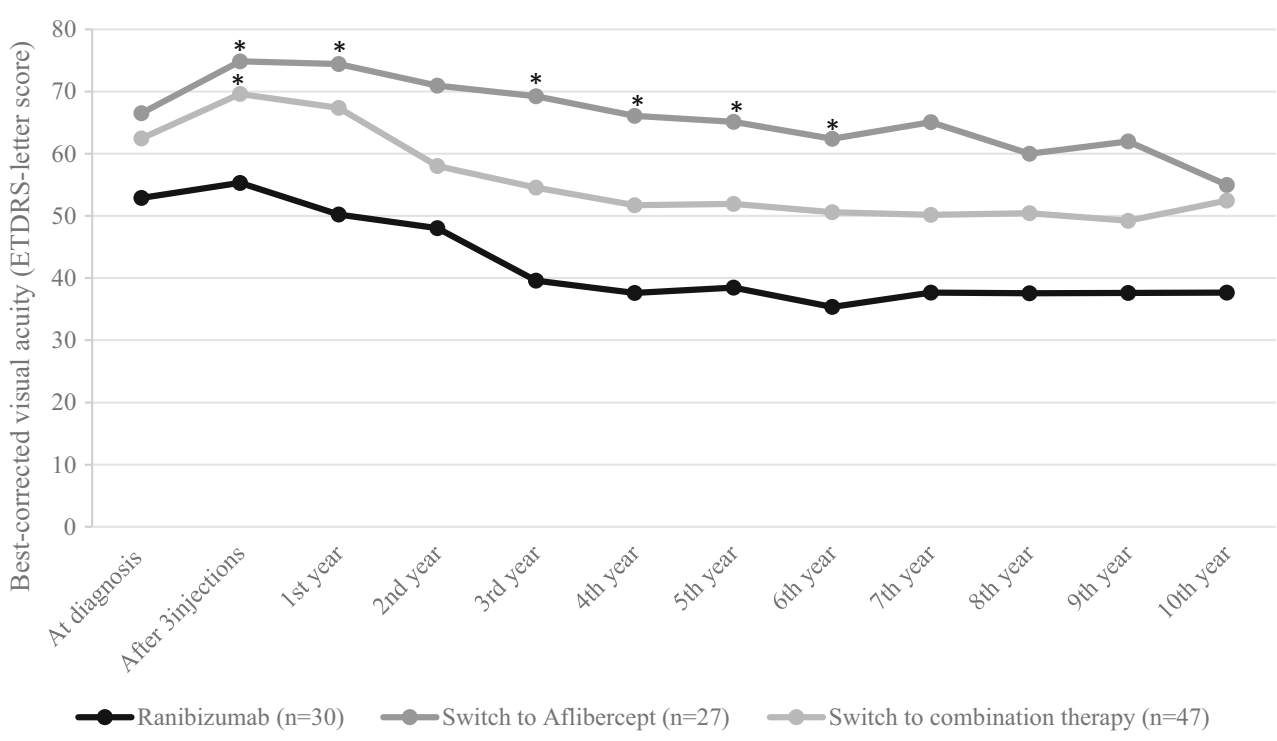

partially accounted for the remarkably better visual outcomes, with a mean loss of only -2.6 letters after 7 years, even though only $11 \%$ of the initial study population had been monitored up to this juncture, compared to $70 \%$ in our own series. Realworld evidence indicates that a loss to follow-up rate of 35$45 \%$ per year has to be expected if visual acuity cannot be stabilized in the early phase [18, 32]. Hence, we believe that the patients' compliance with the treatment regime probably has the greatest bearing on the long-term stability of visual function after the initial treatment phase. With such compliance, a useful long-term function can nowadays be achieved in most of the patients indicated by maintenance of driving vision ( $\geq 0.5$ ) in $55 \%$. In our patients, in comparison, driving vision was found in 43, 48 and $34 \%$ of eyes at diagnosis and after 2, 5 and 7 years, respectively. These results are comparable to the findings of a Scottish study in which the follow-up period was 4.1 years [22]. The fact that patients switching from ranibizumab to aflibercept presented better BCVA scores than non-switchers until 5 years of follow-up reflects the difference in initial pre-treatment BCVA, which did not catch up. The change in BCVA was identical for all three groups over the first 5 years. Based on the retrospective nature of this study, it was neither possible nor the aim of this study to compare treatment effects or strategies.

In conclusion, after more than 7 years of treatment, one third of eyes undergoing long-term treatment has maintained a useful visual acuity allowing reading and driving. Based on the experience gathered during the last decade, newly diagnosed patients with wAMD may achieve even better long-term outcomes. Although our patients may not have received a sufficient number of injections during the early years of treatment, their close compliance with the scheduled visits resulted in a 10 -year visual stability that surpassed the real-life expectations.
Fig. 6 Grouping of study eyes according to best-corrected visual acuity at each point of time

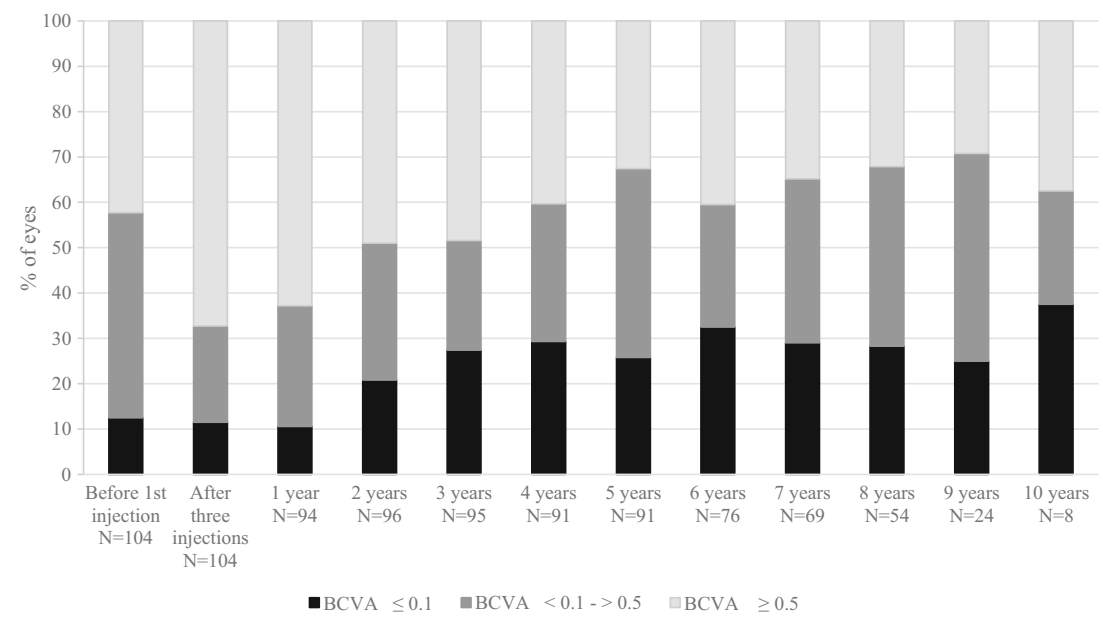


Acknowledgements None of the authors announces any conflict of interest in the context of the data presented herein.

\section{Compliance with ethical standards}

Competing interests JGG advises several pharmaceutical companies (Alcon, Allergan, Bayer, Novartis) and participates in a number of international, multicentre clinical studies that are sponsored by a few of these (Novartis, Bayer) in the fields of AMD and diabetic retinopathy. These activities had no bearing on the study that gave rise to the submitted article, for which JGG received neither direct nor indirect financial support; nor has he conflicts of interest with any of the presented data. The other two authors have no potential conflicts of interest.

Financial disclosure This study did not receive any external funding.

Ethical approval Though formal consent is not required for this type of retrospective study, ethical approval was received by the Institutional Ethics Board (Kantonale Ethikkommission Bern, University of Bern, registration number KEK 99/15).

\section{References}

1. Holz FG, Amoaku W, Donate J, SUSTAIN Study Group et al (2011) Safety and efficacy of a flexible dosing regimen of ranibizumab in neovascular age-related macular degeneration: the SUSTAIN study. Ophthalmology 118:663-671. https://doi.org/10. 1016/j.ophtha.2010.12.019

2. Martin DF, Maguiere MG, Fine SL, CATT Research Group et al (2011) Ranibizumab and bevacizumab for neovascular age-related macular degeneration. N Engl J Med 364:1897-1908. https://doi. org/10.1056/NEJMoa1102673

3. Chakravarthy U, Harding SP, Rogers CA, IVAN study investigators et al (2013) Alternative treatments to inhibit VEGF in age-related choroidal neovascularization: 2-year findings of the IVAN randomized controlled trial. Lancet 382:1258-1267. https://doi.org/10. 1016/S0140-6736(13)61501-9

4. Quaggin SE (2012) Turning a blind eye to anti-VEGF toxicities. J Clin Invest 122:3849-3851. https://doi.org/10.1172/JCI65509

5. Rofagha S, Bhisitkul RB, Boyer DS, SEVEN-UP Study Group et al (2013) Seven-year outcomes in ranibizumab-treated patients in ANCHOR, MARINA, and HORIZON: a multicenter cohort study (SEVEN-UP). Ophthalmology 120:2292-2299. https://doi.org/10. 1016/j.ophtha.2013.03.046

6. Finger RP, Wickremasinghe SS, Baird PN et al (2014) Predictors of anti-VEGF treatment response in neovascular age-related macular degeneration. Surv Ophthalmol 59:1-18. https://doi.org/10.1016/j. survophthal.2013.03.009

7. Muether PS, Hoerster R, Hermann MM et al (2013) Long-term effects of ranibizumab treatment delay in neovascular age-related macular degeneration. Graefes Arch Clin Exp Ophthalmol 251: 453-458. https://doi.org/10.1007/s00417-012-2038-0

8. Michels S, Rosenfeld PJ, Puliafito CA et al (2005) Systemic bevacizumab (Avastin) therapy for neovascular age-related macular degeneration twelve-week results of an uncontrolled open-label clinical study. Ophthalmology 112:1035-1047. https://doi.org/10. 1016/j.ophtha.2005.0.007

9. Rosenfeld PJ, Moshfeghi AA, Puliafito CA (2005) Optical coherence tomography findings after an intravitreal injection of bevacizumab (avastin) for neovascular age-related macular degeneration. Ophthalmic Surg Lasers Imaging 36:331-335. https://doi. org/10.3928/1542-8877-20050701-14
10. Heier JS, Antoszyk AN, Pavan PR et al (2006) Ranibizumab for treatment of neovascular age-related macular degeneration: a phase I/II multicenter, controlled, multidose study. Ophthalmology 113: 633.e1-4. https://doi.org/10.1016/j.ophtha.2005.10.052

11. Kaiser PK, Brown DM, Zhang K et al (2007) Ranibizumab for predominantly classic neovascular age-related macular degeneration: subgroup analysis of first-year ANCHOR results. Am J Ophthalmol 144:850-857. https://doi.org/10.1016/j.ajo.2007.08. 012

12. Rosenfeld PJ, Brown DM, Heier JS, MARINA Study Group et al (2006) Ranibizumab for neovascular age-related macular degeneration. N Engl J Med 355:1419-1431. https://doi.org/10.1056/ NEJMoa054481

13. Heier JS, Brown DM, Chong V et al (2012) Intravitreal aflibercept (VEGF trap-eye) in wet age-related macular degeneration. Ophthalmology 119(12):2537-2548. https://doi.org/10.1016/j. ophtha.2012.09.006

14. Schmidt-Erfurth U, Kaiser PK, Korobelnik JF et al (2014) Intravitreal Aflibercept injection for neovascular age-related macular degeneration. Ophthalmology 121:193-201. https://doi.org/10. 1016/j.ophtha.2013.08.011

15. Bhisitkul RB, Mendes TS, Rofagha S et al (2015) Macular atrophy progression and 7-year vision outcomes in subjects from the ANCHOR, MARINA, and HORIZON studies: the SEVEN-UP study. Am J Ophthalmol 159:915-24.e2. https://doi.org/10.1016/j. ajo.01.032

16. Bhisitkul RB, Desai SJ, Boyer DS et al (2016) Fellow eye comparisons for 7-year outcomes in Ranibizumab-treated AMD subjects from ANCHOR, MARINA, and HORIZON (SEVEN-UP study). Ophthalmology 123:1269-1277. https://doi.org/10.1016/j.ophtha. 2016.01.033

17. Garweg JG (2016) Atrophy of the macula in the context of its wet, age-related degeneration: an inescapable consequence of antiVEGF therapy? Ophthalmologe 113:1036-1045. https://doi.org/ 10.1007/s00347-016-0306-9

18. Holz FG, Tadayoni R, Beatty S et al (2015) Multi-country real-life experience of anti-vascular endothelial growth factor therapy for wet age-related macular degeneration. Br J Ophthalmol 99:220 226. https://doi.org/10.1136/bjophthalmol-2014-305327

19. Munk MR, Ceklic L, Ebneter A et al (2016) Macular atrophy in patients with long-term anti-VEGF treatment for neovascular agerelated macular degeneration. Acta Ophthalmol 94:e757-e764. https://doi.org/10.1111/aos.13157

20. Boulanger-Scemama E, Sayag D, Ha Chau Tran T et al (2016) Ranibizumab and exudative age-related macular degeneration: 5year multicentric functional and anatomical results in real-life practice. J Fr Ophtalmol 39:668-674. https://doi.org/10.1016/j.jfo. 2016.06.001

21. Maguire MG, Martin DF, Ying GS, Comparison of Age-related Macular Degeneration Treatments Trials (CATT) Research Group et al (2016) Five-year outcomes with anti-vascular endothelial growth factor treatment of neovascular age-related macular degeneration: the comparison of age-related macular degeneration treatments trials. Ophthalmology 123:1751-1761. https://doi.org/10. 1016/j.ophtha.2016.03.045

22. Borooah S, Jeganathan VS, Ambrecht AM et al (2015) Long-term visual outcomes of intravitreal ranibizumab treatment for wet agerelated macular degeneration and effect on blindness rates in southeast Scotland. Eye (Lond) 29:1156-1161. https://doi.org/10.1038/ eye. 2015.83

23. Boulanger-Scemama E, Querques G, About F et al (2015) Ranibizumab for exudative age-related macular degeneration: a five year study of adherence to follow-up in a real-life setting. J Fr Ophtalmol 38:620-627. https://doi.org/10.1016/j.jfo.2014. 11.015 
24. Gillies MC, Campain A, Barthelmes D, Fight Retinal Blindness Study Group et al (2015) Long-term outcomes of treatment of Neovascular age-related macular degeneration: data from an observational study. Ophthalmology 122:1837-1845. https://doi.org/10. 1016/j.ophtha.2015.05.010

25. Peden MC, Suñer IJ, Hammer ME et al (2015) Long-term outcomes in eyes receiving fixed-interval dosing of anti-vascular endothelial growth factor agents for wet age-related macular degeneration. Ophthalmology 122:803-808. https://doi.org/10.1016/j.ophtha. 2014.11.018

26. Holz FG, Tadayoni R, Beatty S et al (2016) Determinants of visual acuity outcomes in eyes with neovascular AMD treated with antiVEGF agents: an instrumental variable analysis of the AURA study. Eye (Lond) 30:1063-1071. https://doi.org/10.1038/eye. 2016.90

27. Holz FG, Tadayoni R, Beatty S et al (2016) Key drivers of visual acuity gains in neovascular age-related macular degeneration in real life: findings from the AURA study. Br J Ophthalmol 100:16231628. https://doi.org/10.1136/bjophthalmol-2015-308166

28. Razi F, Haq A, Tonne P et al (2016) Three-year follow-up of ranibizumab treatment of wet age-related macular degeneration: influence of baseline visual acuity and injection frequency on visual outcomes. Clin Ophthalmol 10:313-319. https://doi.org/10.2147/ OPTH.S97775

29. Rasmussen A, Sander B (2014) Long-term longitudinal study of patients treated with ranibizumab for neovascular age-related macular degeneration. Curr Opin Ophthalmol 25:158-163. https://doi. org/10.1097/ICU.0000000000000050

30. Kuehlewein L, Dustin L, Sagong M et al (2016) Predictors of macular atrophy detected by Fundus autofluorescence in patients with Neovascular age-related macular degeneration after long-term Ranibizumab treatment. Ophthalmic Surg Lasers Imaging Retina 47:224-231. https://doi.org/10.3928/23258160-20160229-04

31. Chew EY, Clemons TE, Agrón E, Age-Related Eye Disease Study Research Group et al (2014) Ten-year follow-up of age-related macular degeneration in the age-related eye disease study: AREDS report no. 36. JAMA Ophthalmol 132:272-277. https:// doi.org/10.1001/jamaophthalmol.2013.6636

32. Amstutz CA, Fleischhauer J, Zweifel S et al (2015) Long-term outcome in patients with Intravitreal anti-VEGF therapy for Exudative AMD. Klin Monatsbl Augenheilkd 232:533-537. https://doi.org/10.1055/s-0035-1545673 